\title{
Effects of Coaching Rubrics on Pre-service Teacher Education for Curriculum Development: With Focus on the Promotion of Higher-Order Thinking Skills
}

\author{
Hiroki Yoshida
}

\begin{abstract}
Teacher training universities in Japan are required to develop pre-service teachers" "practical teaching skills" such as skills and understanding for curriculum development. However, it is difficult to provide teachers a clear view of what the learning objectives are in performance tasks. Therefore, this study purposed to promote pre-service teachers' skills and understanding of curriculum development by using a task-specific coaching rubric. Participants were 130 third-year university students who were taking pre-service teacher education courses for elementary and secondary education. Participants were assigned to a treatment group that was provided a rubric in advance of the learning activity and a control group. Participants were required to develop a curriculum and thinking tools with the aim of promoting children's higher-order thinking skills. A task-specific rubric with seventeen criteria and four standard/rating levels was used to assess participants' performance, and a ten-item quiz was used to assess participants understanding. Results of the study show that students who were provided a coaching rubric before undertaking the task scored significantly higher than the control group on both the performance task $(t(95)=5.33, p<.01)$ and quiz $(t(104)=4.75, p<.01)$. Results suggest that coaching rubrics provide pre-service teachers a view of what the learning target is, and they provide students thoughtful judges of the quality of their performance. Given the findings of the study, it is expected to validate and generalize task-specific coaching rubrics which enhance learners' curriculum development skills for higher-order thinking.
\end{abstract}

Index Terms - Coaching rubrics, curriculum development, higher-order thinking skills, pre-service teacher education.

\section{INTRODUCTION}

In order to cope with the development of the knowledge-based society, school systems are required to recognize the significance of learning objectives such as social competence, higher-order thinking, critical thinking, knowledge sharing, and cooperation techniques [1]. The current situation in Japan is not an exception. The Prime Minister of Japan and His Cabinet announced the New Growth Strategy in 2010, and suggested schools to design and organize cooperative/collaborative learning classes in which students teach each other and learn from each other [2]. In 2011, the Ministry of Education, Culture, Sports, Science and Technology-Japan (hereinafter abbreviated as MEXT) announced the Vision of ICT in Education and recommended

Manuscript received May 28, 2015; revised August 24, 2015. This work was supported by JSPS KAKENHI Grant Number 25350360.

Hiroki Yoshida is with Tokoha University, Shizuoka, Japan (e-mail: h-yoshida@av-lab.org). schools to promote "individualized learning responding to each child's abilities and personality, and cooperative learning where children can teach and learn among themselves, in addition to conventional mass learning by guidance all at once. [3]" Thus, elementary and secondary school teachers in Japan are now expected to understand the impact of team-based learning as an approach to cooperative learning, design and implement cooperative learning lessons and activities, and acquire facilitation skills to promote cooperative learning.

With the purpose of improving the quality of teachers in Japan and to facilitate cooperative learning along with individual learning and teacher-centered lectures in elementary and secondary schools, MEXT revised the Educational Personnel Certification Law in June 2007 [4]. Following the revision, a teaching certificate renewal system was introduced in 2009. As a result, a 10 years period was set as the period of validity of regular and special education personnel certificates [5]. In order to renew the period of validity of an education personnel certificate, elementary and secondary teachers must take a renewal course given by teacher training universities every ten years [6]. The renewal course consists of 12 hours or more of compulsory topics and 18 hours or more of elective topics.

Furthermore, the Central Education Council [7] announced teacher training universities to establish a graduate school of education that focuses on teaching profession, and a new curriculum module in pre-service teacher education courses, namely, "seminar for teaching practice" was established so as to enhance pre-service teachers' practical teaching skills. In response to the announcement, the Act for Enforcement of the Education Personnel Certification Act was revised in April 2010, and requested teacher colleges to design and manage the new curriculum module "seminar for teaching practice" as a compulsory module for pre-service teacher training [8].

\section{A. Needs to Foster Students' Higher-Order Thinking Skills in Japan}

Schools in Japan develop their curriculum based on the national standard "Courses of Study." The 6th Courses of Study was revised following the recommendations of the Central Council for Education in 1996. The Council reported in "The Model for Japanese Education in the Perspective of the 21st Century" to encourage students' "zest for living. [9], [10]" "Zest of living" means well-balanced competencies of solid academic capabilities, well-rounded character, and healthy body in order to live in the rapid changing society [11] (see Fig. 1).

However, in 2006, the Central Council for Education 
issued that the descriptions of learning and evaluating methods for realizing curriculum guidelines to foster "zest of life" is insufficient. The Council commented that 1) teachers lack understanding of the concept of "zest of life," 2) teachers are putting too much weight on autonomous learning, 3) teachers are finding difficulty to link between basic knowledge and skill attainment and exploratory and/or problem-solving activities, 4) teachers lack time to design and manage classes that focus on higher-order thinking, and 5) homes and communities lack educational capacity to nurture rich spirit and healthy bodies [12].

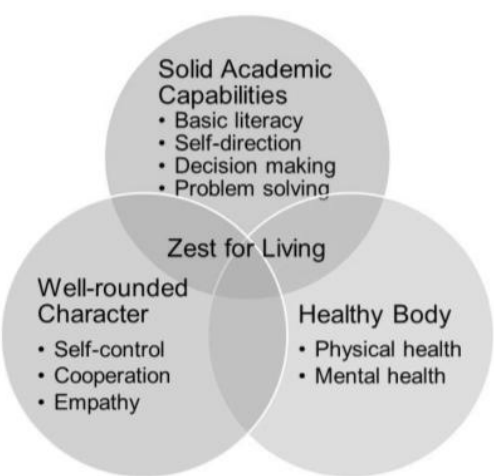

Fig. 1. Structure of "Zest for Living" (source: MEXT, 2010, translated by author).

Following the Council's report, the Basic Act on Education which sets national aims and goals of education in Japan was revised. The Basic Act defines that "education shall aim for the full development of personality and strive to nurture the citizens, sound in mind and body, who are imbued with the qualities necessary for those who form a peaceful and democratic state and society [13]." It was enacted in March 1947 and was revised in December 2006 for the first time in approximately 60 years [14]-[16].

Along with the revision of the Basic Act on Education, the School Education Act was amended in 2006 requiring elementary schools to develop pupils' basic literacy, to promote their thinking skills, decision-making and expression skills, and to foster positive attitude toward learning. In reaction to the amendment of the School Education Act, the Courses of Study was revised in 2008 with the emphasis to cultivate students' "zest for life," by balancing attainment of basic knowledge and skills with thinking skills, decision-making, and expression skills, and to nurture rich and wholesome heart and body [17].

With response to the revision of the Courses of Study, the Curriculum Research Center, National Institute for Educational Policy Research conducted a five-year research project in order to state a preliminary idea of 21 st century competency in Japanese context, and to specify the contents and composition of "zest for life." The Center studied educational competency-based goals of DeSeCo, the European Union, the United Kingdom, Australia, New Zealand, and the United States, and concluded that there are three tiers of the six goals: 1) basic literacy, such as literacy, numeracy and ICT literacy, 2) higher-order thinking skills, and 3) social skills [18]. Given the findings, the center proposed the "Japanese Version of 21st Century Competency (Fig. 2)" which is composed of 1) basic literacy, 2) higher-order thinking skills, such as logical thinking, critical thinking, and metacognition, and 3) practical ability to take actions in real life [19].

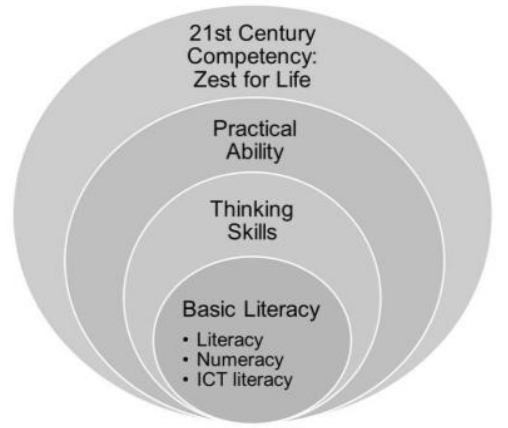

Fig. 2. Japanese version of 21st century competency (source: Curriculum Research Center, translated by author).

Higher-order thinking is stated as thinking that happens in analysis, synthesis, and evaluation rungs [20] of Bloom's ladder [21]. As can be seen, teachers in Japan today are required to foster students' higher-order thinking skills along with their basic knowledge and skills in order to enable students to thrive in the knowledge based-society.

In order to foster students' higher-order thinking in Japan, thinking tools have been recently introduced and implemented in primary and secondary schools [22]-[25]. Thinking tools can be defined as tools that "enable students to represent what they learned and know using different representational formalisms [26]" Thinking tools are used to engage students in higher-order thinking [27], and are used to facilitate a group of people to have common understanding about a certain issue or activity [28]. Thinking tools are also introduced in in-service teacher training courses in Japan [29], [30]. Given such a situation, participants in this study were introduced to thinking tools to enhance elementary and secondary students' higher-order thinking skills.

\section{B. Needs for Performance Evaluation in Japan}

Since the announcement of the first Courses of Study [31] (Tentative Draft) in 1947, elementary and secondary schools in Japan has been implementing norm-referenced evaluation. However, the revised Curriculum Guidance Records which was announced in 1991 [32] underlined the importance of evaluating students' attitude and their learning process, and the necessity to implement criterion-referenced evaluation. Responding to this suggestion, the next Courses of Study that was announced in 1998 [33] adopted criterion-based quantitative evaluation.

Following the revision of the Courses of Study in 1998, the National Institute for Educational Policy Research announced a guideline to develop evaluation criteria, and to improve evaluation methods for elementary and junior high schools in 2002 [34], [35], and emphasized the importance of evaluating students' attitude, performance and learning process. Since then, performance evaluation and rubrics which are rating tools that assess learners' performance have received attention in schools in Japan.

Rubrics can be defined as "specific sets of criteria or scoring guides that organize and clarify the rating criteria and standard for a specific task or target, and clearly defines what a range of acceptable and unacceptable performance looks like at several levels with descriptors [36]-[40]." 
Rubrics are classified by its structure and function. Focusing on its structure, rubrics are classified into two types: holistic rubrics with evaluate the overall performance by on criterion [41], [42], and analytic rubrics which break down the performance into several criteria and assign point value to each [41], [43].

With focus on the range in application, rubrics can be classified into two types: generic/general rubrics that are used to evaluate a process across disciplines and to develop a generic skill or set of skills such as critical thinking or communication across time [44]-[46], and task-specific rubrics that are applicable only for a specific performance or task [44]-[47].

Looking at the function, rubrics can be classified into two types: scoring rubrics that are used to evaluate and score students' work, and coaching rubrics that are used to coach students in order to develop specific skills or to accomplish a specific task [48]-[50].

Under these circumstances, it is important for pre-service elementary and secondary teachers in Japan to develop curricula, lessons, and assessment tools with the purpose of fostering students' higher-order thinking skills. Therefore, this study purposed to identify the effects of coaching rubrics on pre-service teachers' understanding and skills of curriculum development

\section{PURPOSE}

The purpose of this study is to identify the effects of task-specific coaching rubrics on pre-service teachers' understanding and skills of curriculum development for higher-order thinking.

The research questions to be addressed in this study are: 1) What effects do coaching rubrics have on pre-service teachers' understanding of curriculum development? 2) What effects do coaching rubrics have on pre-service teachers' curriculum development skills?

\section{METHOD}

The study was conducted from September 30th to October 7 th, 2014 with the purpose of identifying the effects of coaching rubrics on pre-service teachers' understanding and skills of curriculum development.

\section{A. Participants}

Participants were 130 third-year university students who were taking pre-service teacher education courses for elementary and secondary education.

All of them were participating in an educational technology class, and had already experienced a four-week teaching practice in elementary school. Participants were assigned to a treatment group that was provided a coaching rubric in advance of the learning activity and a control group that was not provided a rubric.

\section{B. Instruments}

Two assessment instruments were used to assess participants' achievement and performance. Mini-quizzes were used to assess participants understanding of curriculum development, and a worksheet was used to evaluate their performance of curriculum development for higher-order thinking. A task-based coaching rubric was used to rate participants' degree of performance of curriculum development.

\section{Procedure}

All of the participants attended an educational technology class. They studied how to design, manage, and evaluate elementary and secondary classroom lessons in order to foster students' higher-order thinking skills. The lesson was structured as follows:

1) Mini-quizzes: $5 \mathrm{~min}$.

2) Comments and advices on the previous week's projectbased activity: $5 \mathrm{~min}$.

3) Lecture on curriculum development for higher-order thinking: $35 \mathrm{~min}$.

4) Instruction on the project-based activity: $5 \mathrm{~min}$.

5) Project-based activity: $40 \mathrm{~min}$.

During the lecture, participants were first instructed what higher-order thinking is. Then they were taught how to develop students' higher-order thinking skills and what kind of higher-order skills are developed in elementary and secondary education. Thirdly, they were introduced to thinking tools such as Venn diagrams (see Fig. 3) and four quadrant diagrams (see Fig. 4). Lastly, participants were explained how to use thinking tools to enhance students' higher-order thinking skills, and the difference between thinking tools and worksheets.

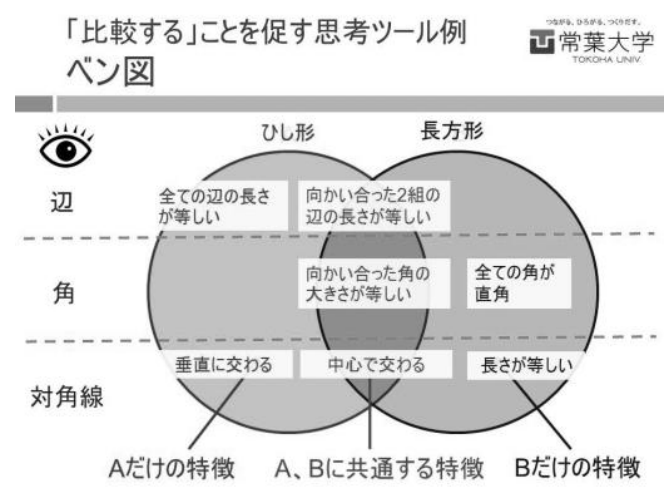

Fig. 3. Example of a venn diagram for higher-order thinking.

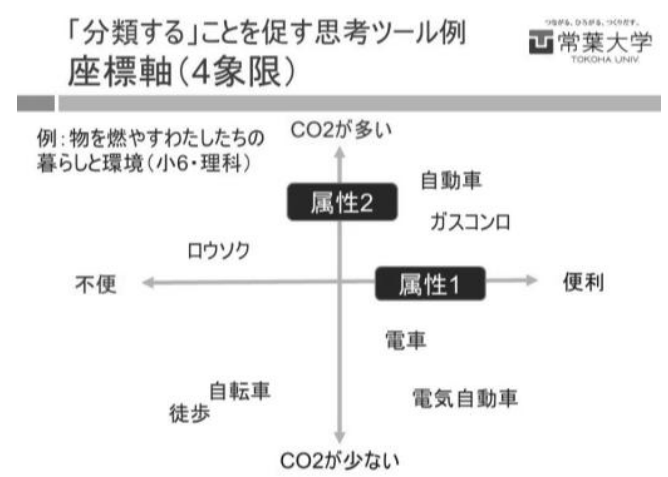

Fig. 4. Example of a four quadrant diagram for higher-order thinking.

After the lecture, participants were instructed on the learning task, and were required to develop a curriculum and thinking tools, with the aim of promoting children's higher-order thinking skills. Fig. 5 shows the outline of the worksheet that was used in this study. 
Instructional Design to Promote Higher-order Thinking Skills

Objective:

\begin{tabular}{|c|c|c|}
\hline & Instructional Activities & Questions \\
\hline 1. Gain attention & & \\
\hline $\begin{array}{l}\text { 2. Inform learner of } \\
\text { objective }\end{array}$ & & \\
\hline $\begin{array}{l}\text { 3. Stimulate stimulus } \\
\text { material }\end{array}$ & & \\
\hline $\begin{array}{l}\text { 4. Present stimulus } \\
\text { material }\end{array}$ & & \\
\hline $\begin{array}{l}\text { 5. Provide learning } \\
\text { guidance }\end{array}$ & & \\
\hline 6. Elicit performance & & \\
\hline 7. Provide feedback & & \\
\hline $\begin{array}{l}\text { 8. Assess } \\
\text { performance }\end{array}$ & & \\
\hline $\begin{array}{l}\text { 9. Enhance retention } \\
\text { and transfer }\end{array}$ & & \\
\hline
\end{tabular}

Target thinking skills

Key thinking tool
Fig. 5. Outline of the worksheet used in this study (translated by author).

A task-specific coaching rubric with seventeen criteria and four standards/rating levels: S (Exceeds expectations), A (Meets expectations), B (Needs Improvement), C (Inadequate) was used to assess participants' performance, and a ten-item quiz was used to assess participants understanding. Fig. 6 shows the outline of the rubric used in this study.

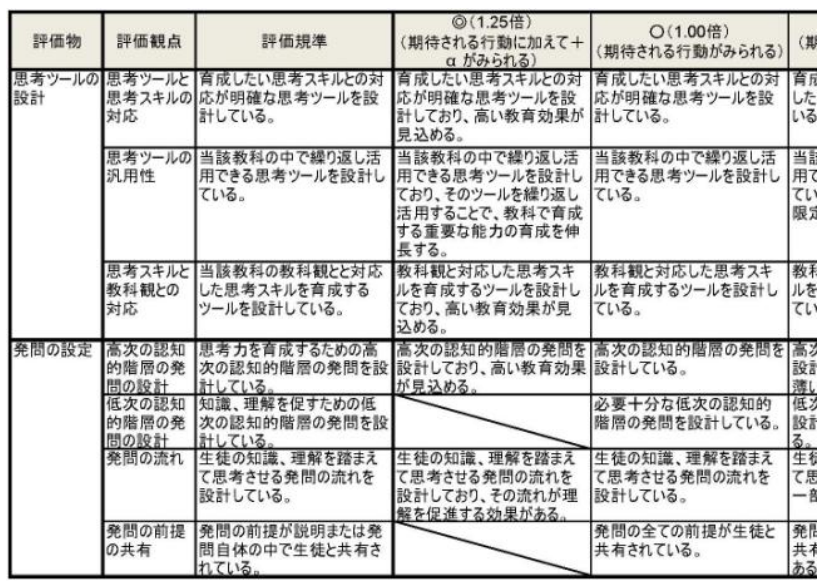

Fig. 6. Outline of the coaching rubric used in this study.
Set out below are examples of the criteria and standards of the rubric.

1) Item: Thinking Tool

Criteria one: Association between the thinking tool and the corresponding thinking skill

- $\mathrm{S}$ : Has designed a thinking tool which is associated with the corresponding thinking skill, and is highly effective.

- A: Has designed a thinking tool which is associated with the corresponding thinking skill.

- B: Has designed a thinking tool which is associated with the corresponding thinking skill, but is less effective.

- $\mathrm{C}$ : Has designed a thinking tool which is not associated with the corresponding thinking skill.

Criteria two: Versatility of the thinking tool

- S: Has designed a thinking tool which can be used repetitively in a particular subject, and fosters significant abilities that are developed in the subject.

- A: Has designed a thinking tool thinking tool which can be used repetitively in a particular subject.

- B: Has designed a thinking tool which can be used repetitively in a particular subject but is of limited use.

- C: Has designed a thinking tool which cannot be used repetitively in a particular subject.

Criteria three: Association between the thinking tool and subject characteristics

- $\mathrm{S}$ : Has designed a thinking tool which is associated with the subject characteristics and is highly effective.

- A: Has designed a thinking tool which is associated with the subject characteristics.

- B: Has designed a thinking tool which is associated with the subject characteristics, but is less effective.

- $\mathrm{C}$ : Has designed a thinking tool which is not associated with the subject characteristics.

2) Item: Questions

Criteria one: Design of questions for higher-order thinking

- S: Has designed divergent questions that enhance students' higher-order thinking skills and are highly effective.

- A: Has designed questions that enhance students' higher-order thinking skills.

- B: Has designed questions that enhance students' higher-order thinking skills but are less effective.

- C: Has not designed questions that enhance students' higher-order thinking skills.

Criteria two: Design of low-order questions

- S: N/A

- A: Has designed reasonable amount of questions that check students' knowledge and understanding.

- B: Has designed questions that check students' knowledge and understanding but the amount of questions is not sufficient.

- C: Has not designed questions that check students' knowledge and understanding.

Criteria three: Flow of questions

- S: The flow of the questions is based on students' knowledge and understanding and promotes students' understanding of the lesson.

- A: The flow of the questions is based on students' knowledge and understanding.

- B: The flow of the questions is based on students' 
knowledge and understanding but part of the questions are ambiguous.

- C: The flow of the questions is not based on students' knowledge and understanding.

Criteria four: Adequate instruction as premises of the questions

- S: N/A

- A: All of the premises of the questions are shared between the teacher and the students.

- B: Some of the premises of the questions are not shared between the teacher and the students.

- C: Most of the premises of the questions are not shared between the teacher and the students.

As the rubric was used to enhance participants' skills and understanding of curriculum development for higher-order thinking, it was provided to the participants in advance of the project-based activity.

\section{RESULtS}

All of the 130 participants completed the learning task and mini-quizzes. This means that the response rate was 100.00 percent. Hereinafter, results of the 130 answers will be introduced.

\section{A. Participants' Profile}

Table I shows the breakdown of participants by gender and teacher education courses they enrolled.

\begin{tabular}{|c|c|c|c|c|c|}
\hline \multicolumn{2}{|c|}{ Profile of participants } & \multicolumn{2}{|c|}{ Treatment group } & \multicolumn{2}{|c|}{ Control group } \\
\hline & & $\mathrm{F}$ & $\%$ & $\mathrm{~F}$ & $\%$ \\
\hline \multirow{3}{*}{ Gender } & Male & 22 & $33.33 \%$ & 26 & $40.63 \%$ \\
\hline & Female & 44 & $66.66 \%$ & 38 & $59.38 \%$ \\
\hline & Total & 66 & $100.00 \%$ & 64 & $100.00 \%$ \\
\hline \multirow{4}{*}{$\begin{array}{l}\text { Teacher } \\
\text { education } \\
\text { courses } \\
\text { enrolled } \\
\text { (multiple } \\
\text { answers) }\end{array}$} & $\begin{array}{l}\text { Kindergarten } \\
\text { education }\end{array}$ & 5 & $7.58 \%$ & 7 & $7.81 \%$ \\
\hline & $\begin{array}{l}\text { Elementary } \\
\text { education }\end{array}$ & 66 & $100.00 \%$ & 64 & $100.00 \%$ \\
\hline & $\begin{array}{l}\text { Secondary } \\
\text { education }\end{array}$ & 50 & $75.76 \%$ & 57 & $89.06 \%$ \\
\hline & $\begin{array}{l}\text { Special needs } \\
\text { education }\end{array}$ & 18 & $27.27 \%$ & 16 & $25.00 \%$ \\
\hline
\end{tabular}

About two-thirds of the participants were women. The reason for the large proportion of the females is that 93.4 percent of kindergarten teachers and 62.5 percent of elementary school teachers in Japan are females [51], and all of the participants enrolled in an elementary education pre-service teacher education course.

\section{B. Effects of Coaching Rubrics on Understanding of Curriculum Development}

Participants' understanding of curriculum development for higher-order thinking was evaluated by a ten-item quiz on a ten-point scale. Effects of coaching rubrics were examined by comparing participants' scores of mini-quizzes on curriculum development for higher-order thinking. For evaluation of the differences, Student's one-tailed $t$-test was used.

Table II shows the effects of coaching rubrics on curriculum development for higher-order thinking. Results indicate that learners' understanding of curriculum development significantly increased by the usage of coaching rubrics $(t(104)=4.75, p<.00)$.

TABLE II: EFFECTS OF COACHING RUBRICS ON UNDERSTANDING OF CURRICULUM DEVELOPMENT

\begin{tabular}{l|r|r|r|r|r}
\hline \hline & $\begin{array}{c}\text { Treatment } \\
\text { Group, mean } \\
\text { (SD) }\end{array}$ & $\begin{array}{c}\text { Control } \\
\text { Group, mean } \\
\text { (SD) }\end{array}$ & $d f$ & $t$ & $P$ \\
\hline $\begin{array}{l}\text { Understanding of } \\
\text { Curriculum } \\
\text { Development }\end{array}$ & 8.48 & 7.01 & 104 & 4.75 & $<.00$ \\
\hline \hline
\end{tabular}

\section{Effects of Coaching Rubrics on Curriculum Development Skills}

Participants' performances of curriculum development for higher-order thinking were evaluated by a seventeen criteria task-specific rubric on a 30 point scale. Effects of coaching rubrics were examined by comparing participants' scores of the learning task on curriculum development for higher-order thinking. For evaluation of the differences, Student's one-tailed $t$-test was used.

Table 3 shows the effects of coaching rubrics on the development of participants' curriculum development skills for higher-order thinking. Results indicate that learners' curriculum development skills significantly increased by the usage of coaching rubrics $(t(95)=5.33, p<.00)$.

TABLE III: EFFECTS OF COACHING RUBRICS ON CURRICULUM DEVELOPMENT SKILLS

\begin{tabular}{l|r|r|c|c|c}
\hline \hline & $\begin{array}{c}\text { Treatment Group, } \\
\text { mean (SD) }\end{array}$ & $\begin{array}{c}\text { Control Group, } \\
\text { mean (SD) }\end{array}$ & $d f$ & $t$ & $P$ \\
\hline $\begin{array}{l}\text { Curriculum } \\
\text { Development }\end{array}$ & 25.18 & 22.03 & 95 & 5.33 & $<.00$ \\
Skills & $(2.23)$ & $(4.20)$ & & \\
\hline \hline
\end{tabular}



Fig. 7. Example of a venn diagram developed by the participants.

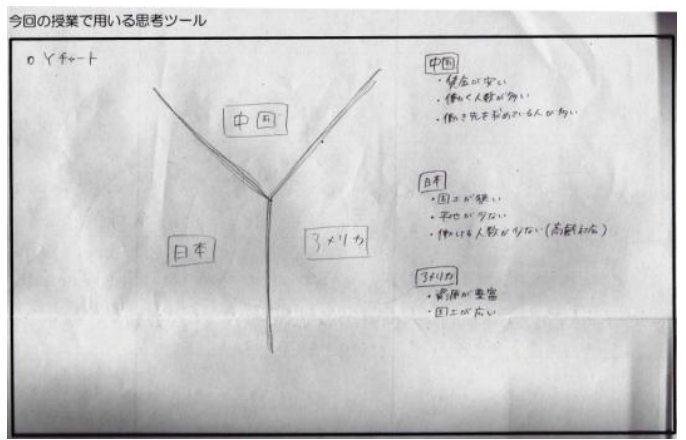

Fig. 8. Example of a Y chart developed by the participants. 
Fig. 7 and Fig. 8 are examples of thinking tools that were developed by the participants.

\section{DISCUSSION}

The purpose of the study was to identify the effects of task-specific coaching rubrics on pre-service teachers' understanding and skills of curriculum development for higher-order thinking.

Regarding the first research question "What effects do coaching rubrics have on pre-service teachers' understanding of curriculum development?," results of the study show that students who were provided a task-specific coaching rubric scored significantly higher on the mini-quizzes compared with the control group $(t(104)=4.75, p<.01)$. Results of the study indicate that if learners are provided a task-specific coaching rubric that focus on what is important for developing a curriculum for higher-order thinking, they could increase understanding on the elements and features of curriculum development. That is to say that the criteria and standards introduced in the coaching rubric leads to the increase of students' knowledge and understanding of the topic.

With regard to the second research question "2) What effects do coaching rubrics have on pre-service teachers' curriculum development skills?," results of the study show that learners who were provided a coaching rubric before undertaking the task scored significantly higher on the performance task compared with the control group $(t(95)=$ $5.33, p<.00)$. Results of the study suggest that if students were provided a task-specific coaching rubric in advance of a learning activity, they could understand what is important in curriculum development. This means that the criteria and standards of coaching rubrics provide learning guidance [52] for learners.

\section{CONCLUSION}

Results of the present study suggest that task-specific coaching rubrics enhance learners' knowledge and understanding of curriculum development for higher-order thinking, and promote learners' skills to develop a curriculum for higher-order thinking. Results indicate that task-specific coaching rubrics provide a view of what the learning target is, and they provide students thoughtful judges of the quality of their performance.

Given the findings of the study, it is expected to validate and generalize task-specific coaching rubrics which enhance learners' curriculum development skills for higher-order thinking. Future study must also focus on developing general rubrics in order to enhance students' higher-thinking skills such as critical thinking and metacognition, along with task-specific rubrics.

As the participants of the present study were Japanese pre-service teachers who are taking teacher education courses in university, it is recommended to use other samples from other ages, nationality, and prior teaching experience for future generalization. Especially, it is meaningful to investigate the effects of coaching rubrics on in-service teachers' understanding and skills of curriculum

\section{development.}

It is important for pre-service teachers in Japan who are required to foster students' higher-order thinking skills to experience, understand, and design curriculums and lessons for higher-order thinking. Therefore, it is significant to introduce pre-service teachers to thinking tools that are used to facilitate students' higher-order thinking skills, and rubrics that are used to evaluate performance of higher-order thinking.

In addition, findings of this study are expected to contribute to suggest teacher educators how to promote pre-service teachers' understandings and skills in curriculum development, and consequently lead to produce skilled, quality teachers to elementary and secondary schools.

\section{ACKNOWLEDGMENT}

This work was supported by JSPS KAKENHI: Grant-in-Aid for Scientific Research (C), Grant Number 25350360 .

\section{REFERENCES}

[1] Y. Punie, D. Zinnbauer, and M. Cabrera, A Review of the Impact of ICT on Learning, European Commission, Seville, Spain: Joint Research Centre, Institute for Prospective Technological Studies, ch. 7, 2006.

[2] Prime Minister of Japan and His Cabinet. (June 2010). New growth strategy. Prime Minister of Japan and His Cabinet. [Online]. Available: http://www.kantei.go.jp/jp/sinseichousenryaku/sinseichou01.pdf

[3] Ministry of Education, Culture, Sports, Science and Technology, The Vision for ICT in Education - Toward the Creation of a Learning System and Schools Suitable for the 21st Century, Tokyo: Ministry of Education, Culture, Sports, Science and Technology, ch. 1, pp. 4-8, 2011.

[4] Elementary and Secondary Education Bureau, MEXT 2007, Tokyo, Japan: Ministry of Education, Culture, Sports, Science and Technology, pp. 8-9, 2007.

[5] Ministry of Education, Culture, Sports, Science and Technology, FY 2007 White Paper on Education, Culture, Sports, Science and Technology: Promoting Educational Reforms Based on the Revised Basic Act on Education/Reform of Elementary and Secondary Education to Usher in a New Era of Education, Tokyo, Japan: Ministry of Education, Culture, Sports, Science and Technology, ch. 1, pp. 5-17, 2008.

[6] National Institute for Educational Policy Research. (March 2011). Teacher training and certificate system. [Online]. Available: http://www.nier.go.jp/English/educationjapan/pdf/201103TTCS.pdf

[7] Central Education Council. (November 2006). How teacher education should be conducted in the future. [Online]. Available: http://www.mext.go.jp/a_menu/koutou/kyoin/1268600.htm

[8] Teacher Education Accreditation Board. (March 2008). Points to consider for conducting the seminar for teaching practice. [Online]. Available:

http://www.mext.go.jp/component/a_menu/education/detail/__icsFile s/afieldfile/2013/02/25/1267752_05.pdf

[9] Central Council for Education, The Model for Japanese Education in the Perspective of the Twenty-First Century, Tokyo: Central Council for Education, part 2, ch. 1, 1996.

[10] Ministry of Education, Culture, Sports, Science and Technology, Japanese Government Policies in Education, Science, Sports and Culture 1996, Tokyo: Ministry of Education, Culture, Sports, Science and Technology, ch. 3, 1996.

[11] Ministry of Education, Culture, Sports, Science and Technology. (2010). "Zest for living": Pamphlet for Parents. [Online]. Available: http://www.mext.go.jp/a_menu/shotou/new-cs/pamphlet/_icsFiles/af ieldfile/2011/07/26/1234786_1.pdf

[12] Central Council for Education, Report on the Improvement of the Courses of Study for Kindergarten, Elementary School, Secondary School, and Special-needs School, Tokyo: Central Council for Education, ch. 4, 2006.

[13] Ministry of Education, Culture, Sports, Science and Technology-Japan. (December 2006). Basic act on education (Provisional translation). 
[Online $]$.

http://www.mext.go.jp/english/lawandplan/1303462.htm

Available:

[14] Ministry of Education, Culture, Sports, Science and Technology-Japan, FY 2005 White Paper on Education, Culture, Sports, Science and Technology: Efforts in Education Rebuilding / Realization of a Nation Based on Culture and the Arts, Tokyo, Japan: Ministry of Education, Culture, Sports, Science and Technology, ch. 1, pp. 3-30, 2006

[15] Ministry of Education, Culture, Sports, Science and Technology-Japan (December 2006). About the new basic act on education. [Online]. Available: http://www.mext.go.jp/b menu/kihon/houan.htm

[16] Ministry of Education, Culture, Sports, Science and Technology-Japan, The Development of Education in Japan 2005-2008, Tokyo, Japan: Ministry of Education, Culture, Sports, Science and Technology, part II, ch 1, pp. 60-64, 2008.

[17] Ministry of Education, Culture, Sports, Science and Technology. (March 2008). Courses of study: 8th edition. [Online]. Available: http://www.mext.go.jp/a_menu/shotou/new-cs/youryou/syo/

[18] Curriculum Research Center, National Institute for Educational Policy Research, Basic Principles of Curriculum Design for Competencies and Skill Building towards Social Changes, Tokyo: National Institute for Educational Policy Research, pp. 13-14, 2013.

[19] Curriculum Research Center, National Institute for Educational Policy Research, Basic Principles of Curriculum Design for Competencies and Skill Building towards Social Changes, Tokyo: National Institute for Educational Policy Research, pp. 83-84, 2013

[20] Teach for America. (2011). Teaching higher-order thinking. Teach for America. [Online]. Available: http://teachingasleadership.org/sites/default/files/Related-Readings/L T_Ch5_2011.pdf

[21] B. S. Bloom, M. D. Engelhart, E. J. Furst, W. H. Hill, and D. R Krathwohl, Taxonomy of Educational Objectives, Handbook I: The Cognitive Domain, New York: David McKay Co Inc, 1956.

[22] N. Ide, "Class activity to raise a child creating the school life that is better than oneself - Through the talks activity that visualization, operation of the information made use of becoming it in - Bulletin of Fukuoka University of Education," vol. 63, no. 6, pp.1-8, 2014.

[23] M. Kurishiba, T. Nakamura, N. Ohnuma, C. Koike, A. Saito, M. Saso, M. Shiga, M. Naruge, H. Nishijima, E. Yokoyama, and T. Yokoyama, "A study to develop a new support tool that enables multiple participants to cocreate an idea and user scenario with the dialogue," Bulletin of the Information Science Center, Senshu University, vol. 34 pp. 1-21, 2013.

[24] Y. Uchida, A. Nishimoto, and H. Taguchi, "Introduction of system thinking to the ability to think, make decision and express oneself in technology education," Journal of the Japan Society of Technology Education, Kyushu Branch, vol. 21, pp. 15-22, 2014

[25] S. Fujieda, "A study on application for moral education of a learning system to promote reconstitution on grounds of thought and judgment: 'The 8 in 4 problem-solving system' incorporated 'matrix method'," Bulletin of Okayama University Graduate School of Education, vol. 158, pp. 1-10, 2015.

[26] Y. Rosen and M. Tager, "Evidence-centered concept map as a thinking tool in critical thinking computer-based assessment," Pearson Research Report, 2013, p. 3.

[27] Y. Rose and M. Mosharraf, "Making student thinking visible through thinking tools in technology-enhanced assessment for learning," in Proc. International Association for Educational Assessment Conference, 2014, pp. 1-20.

[28] D. H. Peters, "The application of systems thinking in health: Why use systems thinking?" Health Research Policy and Systems, vol. 12, no. 1 pp. 1-6, 2014.

[29] S. Fujieda, "Practice of the class that utilized the function of 'matrix method' instruction of junior high school social studies with the class group formation by 'Cooperative Collaboration Learning' as a base," Bulletin of Center for Teacher Education and Development, Okayama University, vol. 5, pp. 101-110, 2015.

[30] A. Nishimoto, H. Taguchi, and N. Hagimine, "Implementation thinking framework and dialogue workshop for teacher in technology Education," Journal of the Japan Society of Technology Education, Kyushu Branch, vol. 20, pp. 15-22, February 2013.

[31] Ministry of Education. (March 1947). Courses of study (Tentative draft). Ministry of Education. [Online]. Available: https://www.nier.go.jp/guideline/s22ej/index.htm
[32] Ministry of Education, Curriculum Guidance Records, 6th Edition Ministry of Education, 1991

[33] Ministry of Education. (March 1998). Courses of Study. Ministry of Education.

[Online].

Available: https://www.nier.go.jp/guideline/h10e/index.htm

[34] National Institute for Educational Policy Research. (February 2002) Guideline for developing evaluation criteria, and improving evaluation methods: For elementary schools. National Institute for Educational Policy Research. [Online]. Available: http://www.nier.go.jp/kaihatsu/houkoku/index_e.htm

[35] National Institute for Educational Policy Research. (2002). Guideline for developing evaluation criteria, and improving evaluation methods For junior high schools. National Institute for Educational Policy Research. [Online]. Available: http://www.nier.go.jp/kaihatsu/houkoku/index_jh.htm

[36] G. Wiggins, Educative Assessment: Designing Assessments to Inform and Improve Student Performance, CA: Jossey Bass Publishers, 1998

[37] P. W. Airasian, Classroom Assessment, NY: McGraw-Hill, 1991.

[38] R. J. Stiggins, Student-Centered Classroom Assessment, NY: Macmillan Publishing Company, 1994.

[39] M. Suzuki, "The effects of explaining evaluation standards and purposes by introducing rubrics: With focus on beliefs in tests, motivation, and learning strategies," Japanese Journal of Education Psychology, vol. 59, pp. 131-143, 2011.

[40] L. Greenstein, Assessing 21st Century Skills: A Guide to Evaluating Mastery and Authentic Learning, Thousand Oaks, CA: Corwin, ch. 5 , 2012.

[41] T. Ando, "The necessity of general rubrics," Bulletin of the Center of Educational Research and Development, Nara University of Education, vol. 17, pp. 1-10, 2008.

[42] H.-Y. Lim, "Performance-based assessment: Rubrics, web 2.0 tools and language competencies," MEXTESOL Journal, vol. 36, no. 1, pp $1-12,2012$.

[43] K. Matsushita, "Evaluating the quality of learning by utilizing performance evaluation: Based on analysis of the structure of evaluation," Kyoto University Researches in Higher Education, vol. 18, pp. 75-114, 2012.

[44] W. J. Popham, "What's wrong and what's right-with rubrics," Educational Leadership, vol. 55, no. 2, pp. 72- 75, 1997.

[45] M. M. Dornisch and A. S. Mcloughlin, "Limitations of web-based rubric resources: Addressing the challenges," Practical Assessment, Research and Evaluation, vol. 11, no. 3, pp. 1-8., 2006

[46] Y. M. Reddy, "Effect of rubrics on enhancement of student learning," Educate, vol. 7, no. 1, pp. 3-17, 2007.

[47] S. Rogers and S. Graham, The High Performance Toolbox, Evergreen, CO: Peak Learning Systems, 1997, p. 376

[48] N. Ejaz, R. Vera, S. Riester, and Y, Cheng, City Science: Final Report, New York: Cornell University, Cornell Institute for Public Affairs, ch. $1,2013$.

[49] R. McAllum, Recipriocal Teaching: Critical Reflection on Practice, Kairaranga, vol. 15 , no. 1, pp. 26-35, 2014

[50] S. C. Betts and A. McCarthy, "The professional writing initiative: providing support for business students," in Proc. the Academy of Educational Leadership, vol. 15, no. 1, pp. 2-6, 2010.

[51] Ministry of Education, Culture, Sports, science and technology, FY 2013 School Basic Survey, Ministry of Education, Tokyo, 2013.

[52] R. Gagne, The Conditions of Learning, 4th edition, New York: Holt, Rinehart and Winston, ch. 12, 1985.

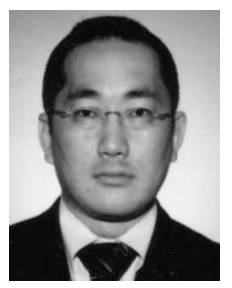

Hiroki Yoshida was born in Nara, Japan in 1973. He received the MEd in educational methodology (audio-visual education) from International Christian University, Tokyo, Japan in 2001

He worked at the Japan Audio Visual Education Association (JAVEA) from April 2000 to March 2002 $\mathrm{He}$ has been teaching pre-service teachers in Tokoha University in Shizuoka, Japan since April, 2002. He is currently a professor at the Faculty of Education, Tokoha University. His research interests include teacher education, online learning, cooperative learning, and hypermedia education. 